\title{
STUDIES
}

\section{Quantifying worldwide economic distress}

\author{
Fernando Delbianco \\ Universidad Nacional del Sur, \\ Argentina \\ E-mail: \\ fernando.delbianco@uns.edu.ar \\ Andrés Fioriti \\ Universidad Nacional del Sur, \\ Argentina \\ E-mail: andres.fioriti@uns.edu.ar

\section{Fernando Tohmé} \\ Universidad Nacional del Sur, \\ Argentina \\ E-mail: ftohme@criba.edu.ar
}

This paper proposes a new measure for worldwide economic distress, which can be described as the proportion of the gross domestic product (GDP) affected by countrylevel financial crises. It proves that this measure has the desirable properties of fair and representative indices. It also adequately justifies the beliefs of some economists that financial crises have negative effects on economic performance.

\author{
Keywords: \\ economic crisis, \\ growth, \\ index
}

\section{Introduction}

Economic crises are disruptive phenomena that have negative effects on the performance of economies. In contemporary market systems, these crises are mostly of a financial nature, although their origins can often be found in the real sector. ${ }^{1}$ Financial channels facilitate the propagation of crises from one country to another, despite policies and other efforts to avoid such events (Reinhart-Rogoff 2009). Therefore, it is of interest for both academic and policy-making reasons to have ways of assessing the impact of these crises. This has been extensively studied at the country level. However, we now pose the question: to what extent can the world be said to be in a state of financial distress? To answer this question, a way of measuring the states of world crises is required.

The objective of this study is to answer this question. We present very simple definitions of two world distress (WD) indices. Indices are widely used in economics to explain a wide range of situations (e.g. Valkó et al. 2017, Akbash et al. 2018).

${ }^{1}$ The rise of commodity prices, for example, has been described as a contributing cause of the sub-prime crisis of 2007, which later triggered the larger crisis that affected developed economies (Breitenfellner et al. 2015).

Regional Statistics, Vol. 9. No. 1. 2019: 3-12; DOI: 10.15196/RS090108 
Similar indices of economic distress have been developed, but at country level (e.g. Angelopoulou et al. 2014, Bhattacharya-Sinha Roy 2009, Choi-Douady 2012, Louzis-Vouldis 2013). This paper shows that our WD indices satisfy the properties of non-triviality (i.e. at least two different values of the indices exist), symmetry (i.e. the indices are independent of the names of the countries involved), normalization (i.e. the indices are in the range $[0,1])$ and weak monotonicity (i.e. if one economy becomes larger, the impact of a crisis cannot be reduced). Each of these assumptions can be contested in certain contexts. However, they represent the usual properties of fair and representative indices as developed by - for example - Sen (1976) and Alkire-Foster (2011).

Using the large database of financial crises at country level developed by Laeven and Valencia (2013), we create time series for the two WD indices in this paper, statistically illustrating the impact of economic crises from 1980 to 2011.2 Furthermore, we run a comparison with the series concerning the growth of the world's GDP, showing that - in general - crises tend to have a negative impact on economic performance. This is expected, and therefore serves as an indirect proof of the soundness of our definition of the WD indices.

Both of our indices are constructed on a global scale, but the same methodology could be used to obtain similar information about individual regions or free trade areas. In this study, we focus on the global level, as we aim to construct an index which allows us to capture worldwide effects. Our aim is to provide a simple measure for the current economic state of the world, which does not demand excessive amounts of information that may be hard to collect. Even though it is simple to apply our index on a regional level, for the purposes of this study, we are concerned with explaining world crises and their GDP implications, rather than regional crises.

The remainder of this paper is structured as follows: Section 2 presents the World Distress Index in its two versions, while Section 3 focuses on their properties. Section 4 provides an empirical argument for the soundness of these indices, and Section 5 concludes the paper.

\section{Definition of the world distress indices}

Laeven and Valencia's (2013) large database of crises from all over the world from 1980 to 2011 provides data concerning different types of financial crises. The main crisis types are banking, currency, and sovereign debt crises. During the period under consideration, Laeven and Valencia (2013) identified 147 banking crises, 211 currency crises, and 66 sovereign debt crises. Our index will be based on a binary indicator function that takes up the value of 1 in the presence of one of those crises. To accomplish this, we first need to understand the differences among them:

${ }^{2}$ We can consider the likelihood of the data being fuzzy and apply some fuzzy methodology as SunantaViertl (2016).

Regional Statistics, Vol. 9. No. 1. 2019: 3-12; DOI: 10.15196/RS090108 
- A banking crisis takes place under the following two conditions:

1. There exist significant signs of financial distress in the banking system and

2. the government intervenes in the banks in response to significant losses for these banks.

- A currency crisis happens if, during a year, the local currency depreciates vis-àvis the United States dollar by at least $30 \%$ and the rate of depreciation is at least 10 percentage points higher than the previous year.

- A sovereign debt crisis occurs if during a year, a country's debt with private investors becomes either defaulted or restructured.

We can now define the indicator function $C(i, t)$, where the first argument $I=1, \ldots, I$ denotes a country (Laeven-Valencia 2013) consider $I=188$ countries) while the second, $t=1, \ldots, T$ represents the year. Then, $C(i, t)=1$ if $i$ suffered one of the aforementioned crises in year $t$, and $C(i, t)=0$ otherwise. For example, since Argentina had all three kinds of crises in 2001 , we have that $C\left(i_{\text {Argentina }}, 2001\right)=1$ while $C\left(i_{\text {Argentina, }}, 2000\right)=0$, because none of them took place in 2000 , where $i_{\text {Argentina }}$ is obviously the index corresponding to Argentina.

$C(i, t)$ can be combined with two different GDP measures. $G D P_{i, t}^{1}$ represents the GDP measured using the purchasing power parity (PPP) of country $i$ during year $t$. Conversely, GDP $P_{i, t}^{2}$ is the GDP of $i$ in $t$, measured in current United States dollars

To construct our indices of worldwide distress $W D_{t}^{k}(k=1,2)$ for a given year $t$, we take, for each country $i$, the product of $C(i, t) G D P_{i, t}^{k}$, and add these terms across countries. We normalize the values by dividing the resulting value by the world $G D P^{k}=\sum_{i=1}^{I} G D P_{i, t}^{k}$ at year $t$. This is expressed as follows:

$$
W D_{t}^{k}=\frac{\sum_{i=1}^{I} C(i, t) G D P_{i, t}^{k}}{\sum_{i=1}^{I} G D P_{i, t}^{k}}
$$

We illustrate the results obtained for $W D^{1}$ and $W D^{2}$ by taking the $I=188$ country indices of Laeven and Valencia (2013) from 1980 to 2011. Table 1 presents the whole index, while Figures 1 and 2 summarize this information. We can see that our two indices highlight four notorious episodes: the general crisis of 1988 with its epicentre in the United States, the developing countries crises of the late 1990s, the dot-com crash of the early 2000s, and the financial crisis of 2007/08. ${ }^{3}$

${ }^{3}$ For more information on these events, see Reinhart-Rogoff (2009).

Regional Statistics, Vol. 9. No. 1. 2019: 3-12; DOI: 10.15196/RS090108 
Table 1

Crises index: PPP and USD

\begin{tabular}{c|c|c|c|c|c}
\hline Year & $W D^{1}$ & $W D^{2}$ & Year & $W D^{1}$ & $W D^{2}$ \\
\hline 1980 & 0.046 & 0.045 & 1996 & 0.074 & 0.047 \\
1981 & 0.073 & 0.066 & 1997 & 0.184 & 0.210 \\
1982 & 0.073 & 0.053 & 1998 & 0.279 & 0.231 \\
1983 & 0.072 & 0.046 & 1999 & 0.121 & 0.158 \\
1984 & 0.059 & 0.034 & 2000 & 0.124 & 0.166 \\
1985 & 0.044 & 0.027 & 2001 & 0.113 & 0.148 \\
1986 & 0.008 & 0.003 & 2002 & 0.011 & 0.005 \\
1987 & 0.006 & 0.003 & 2003 & 0.009 & 0.004 \\
1988 & 0.232 & 0.281 & 2004 & 0.002 & 0.001 \\
1989 & 0.015 & 0.007 & 2005 & 0.001 & 0.000 \\
1990 & 0.065 & 0.036 & 2006 & 0.000 & 0.000 \\
1991 & 0.090 & 0.061 & 2007 & 0.211 & 0.304 \\
1992 & 0.077 & 0.051 & 2008 & 0.410 & 0.553 \\
1993 & 0.107 & 0.058 & 2009 & 0.403 & 0.544 \\
1994 & 0.102 & 0.066 & 2010 & 0.393 & 0.511 \\
1995 & 0.097 & 0.070 & 2011 & 0.386 & 0.494
\end{tabular}

Note: Here and hereinafter, $W D^{1}$ : world distress index using PPP as the GDP measure; $W D^{2}$ : world distress index using USD as the GDP measure.

Our indices, which are easy to understand, provide a simplified way of obtaining an economic picture of the world. For example, the value of $W D^{1}$ in 2007 was 0.211 , which indicates that $21.1 \%$ of the world GDP measured using PPP was in crisis. Moreover, the index level increasing to $41 \%$ in 2008 means that the world GDP affected by the financial crisis increased sharply. Subsequent years saw a decrease in the exposure of the world GDP to the crisis, with diminishing levels of both $W D^{1}$ and $W D^{2}$. 


\section{PPP crisis index}

Figure 1

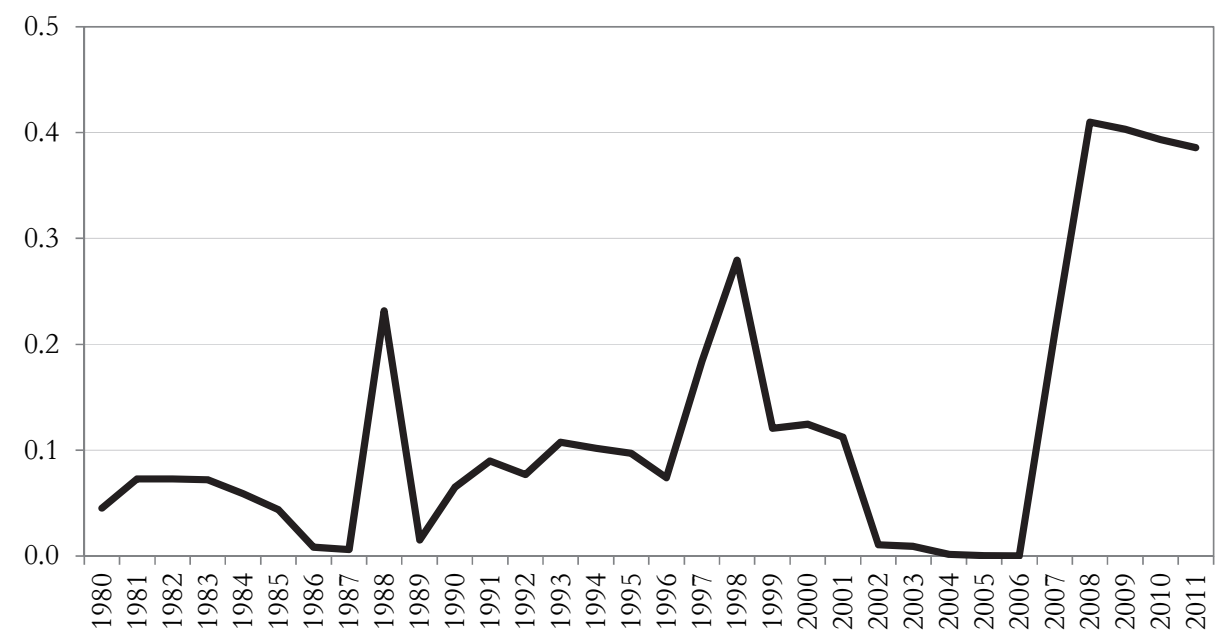

Note: Here and hereinafter, PPP: purchasing power parity.

Figure 2

\section{USD crisis index}

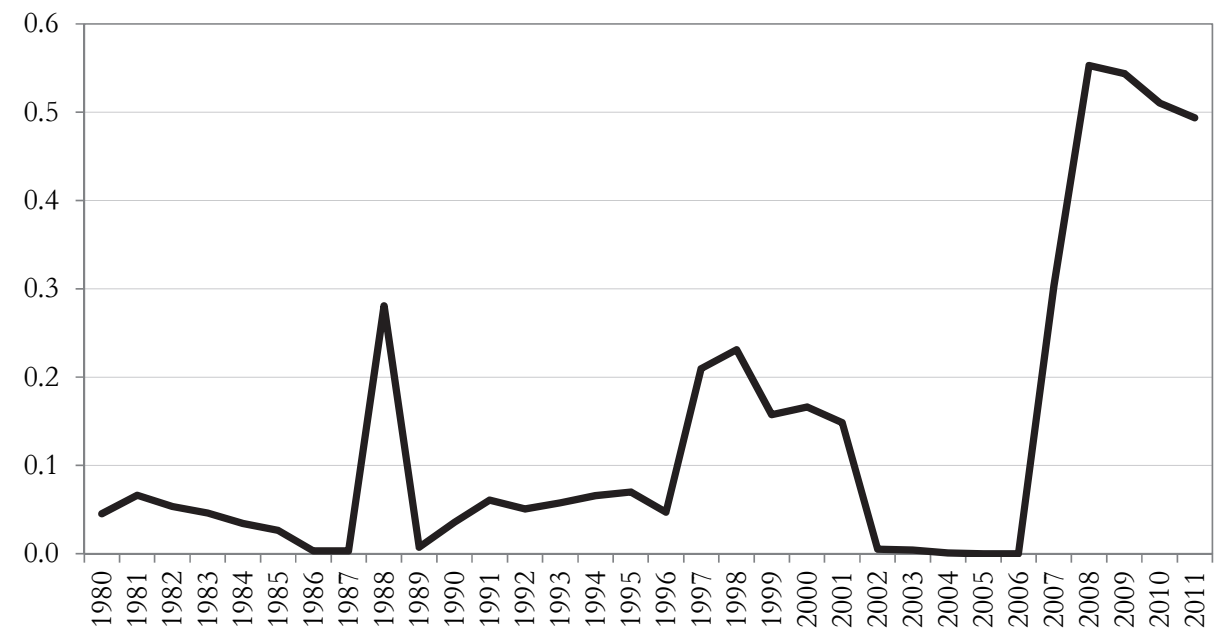

Institutions such as the International Monetary Fund or the Organisation for Economic Co-operation and Development generate appraisals with similar objectives by estimating the percentage of deviation of the global GDP from its historical trend or by comparing the world GDP with its pre-crisis level. Both of these indices are defined in relation to measures that, by themselves, may be sensitive to how they 
are defined, such as the world trend or the pre-crisis global GDP. In this regard, our indices are easier to compute, since we require only a dummy of a crisis for each country and country-level GDP measures.

\section{Properties}

There are four properties that a fair and balanced index should satisfy. In our case, it means that each country-level crisis should contribute to $W D_{t}^{k}$ in proportion to its contribution to the world's GDP. ${ }^{4}$ While it is intuitively obvious that $W D^{\mathrm{k}}$ satisfies these properties, we confirm whether this is the case.

Definition 1 (Non-triviality). The range of values of each index has at least two distinct values, that is, $\left|\operatorname{Range}\left(W D_{t}^{k}\right)\right|>1$.

Non-Triviality is a standard condition for indices. If this condition was not satisfied, it would mean that the state of distress of the world (described by the index) remains constant, rendering the index meaningless. The proof follows trivially from the fact that the indices at any $t$ obtain as weighted averages of values $C(i, t)=1$ or $C(i, t)=0$ for every $i$.

This last point also indicates the validity of:

Definition 2 (Normalization). The range of both indices has a minimum value of 0 and a maximum value of 1 . That is, for every $t, W D_{t}^{k} \in[0,1]$.

Normalization allows for a comparison across time, without having to be concerned with the changes of GDP in time. Since (1) has $\sum_{i=1}^{I} G D P_{i, t}^{k}$ as the denominator, we can guarantee that the index cannot surpass 1 . Conversely, since the numerator's lowest value can only be 0 (the denominator is always positive), the index cannot be lower than 0 .

Another obvious property satisfied by our indices is:

Definition 3 (Symmetry). If the identities of the countries are permuted, the crises indices remain unchanged.

The importance of this requirement lies in that it avoids 'nominal' traps, for instance the status of a country in world affairs that increases or lowers the world distress by having a crisis. While it is true that a crisis started in a country with strategic relevance may have a more significant impact on the rest of the world, usually, this strategic importance is highly correlated to its GDP. Therefore, the change in names would not affect the value of $W D^{k}$ much.

${ }^{4} \mathrm{By}$ a slight abuse of language, we will use $k$ to represent in a single expression both indices, where either $k=1$ or $k=2$, measuring the GDP in PPP or in current USD respectively.

Regional Statistics, Vol. 9. No. 1. 2019: 3-12; DOI: 10.15196/RS090108 
Finally, we have

Definition 4 (Weak monotonicity). Other factors being equal, an increase in income of a country in crisis cannot decrease the crisis indices. That is, if $C(i, t)=1$, an increase from $G D P_{i, t}^{k}$ to $G D P_{i, t}^{k}$, cannot lead to a decrease from $W D_{t}^{k}$ to $W D_{t}^{k \prime}$ if $G D P_{i, j}^{k}$ and $C(j, t)$ remain invariant for $j \neq i$.

Weak monotonicity refers to the fact that bigger countries should have a higher impact on the index. Therefore, if a country gets bigger even while in crisis, the index should be at least as high as before, since the 'importance' of this country has grown and with it its contribution to the global crisis level. Our indices satisfy this condition:

Proof: Suppose there exists at least a country $j$ for which we have $C(j, t)=1$ and assume that $W D_{t}^{k}>0$. Next, increase $G D P_{j, t}^{k}$ by $\epsilon>0$, leaving all other variables unchanged. ${ }^{5}$ This leads to a new value for the index, $W D_{t}^{k \prime}$.

If

$$
W D_{t}^{k}=\frac{\sum_{i=1}^{I} C(i, t) G D P_{i, t}^{k}}{\sum_{i=1}^{I} G D P_{i, t}^{k}}
$$

we have that

$$
\begin{aligned}
W D_{t}^{k \prime} & =\frac{\sum_{i \neq j} C(i, t) G D P_{i, t}^{k}+C(j, t)\left(G D P_{j, t}^{k}+\epsilon\right)}{\sum_{i \neq j} G D P_{i, t}^{k}+\left(G D P_{j, t}^{k}+\epsilon\right)} \\
& =\frac{\sum_{i=1}^{I} C(i, t) G D P_{i, t}^{k}+C(j, t) \epsilon}{\sum_{i=1}^{I} G D P_{i, t}^{k}+\epsilon} .
\end{aligned}
$$

Since $C(j, t)=1$ and calling $\alpha=\sum_{i=1}^{I} C(i, t) G D P_{i, t}^{k}$ and $\beta=\sum_{i=1}^{I} G D P_{i, t}^{k}$, the last expression means that

$$
W D_{t}^{k \prime}=\frac{\alpha+\epsilon}{\beta+\epsilon}
$$

as $W D_{t}^{k}=\frac{\alpha}{\beta}$ if the claim was false, we could have that $W D_{t}^{k}>W D_{t}^{k \prime}$, that is,

$$
\frac{\alpha}{\beta}>\frac{\alpha+\epsilon}{\beta+\epsilon} .
$$

Next, a trivial algebraic manipulation shows that this is equivalent to:

$$
\alpha>\beta
$$

which contradicts the fact that $\frac{\alpha}{\beta}=W D_{t}^{k} \leq 1$.

Therefore, $W D_{t}^{k} \leq W D_{t}^{k \prime}$. (End proof)

${ }^{5}$ Notice that if $C(i, t)=1$ for every $t$, increasing the income of any country will not increase the index, since it will remain equal to 1 . Analogously, if $C(i, t)=0$ for every $i$, the index will remain equal to 0 .

Regional Statistics, Vol. 9. No. 1. 2019: 3-12; DOI: 10.15196/RS090108 


\section{Soundness}

To determine whether our definitions capture in some way the impacts of crises, we regress the world's GDP against one of our WD indices. We use the World Bank dataset as a source, selecting the PPP world GDP growth, that is, $W D^{1}$.

At first glance, Figure 3 indicates a clear negative relationship for the 2007/2008 crises. However, for previous crises, the relationship is not clear.

Figure 3

\section{World GDP growth and the WD index}

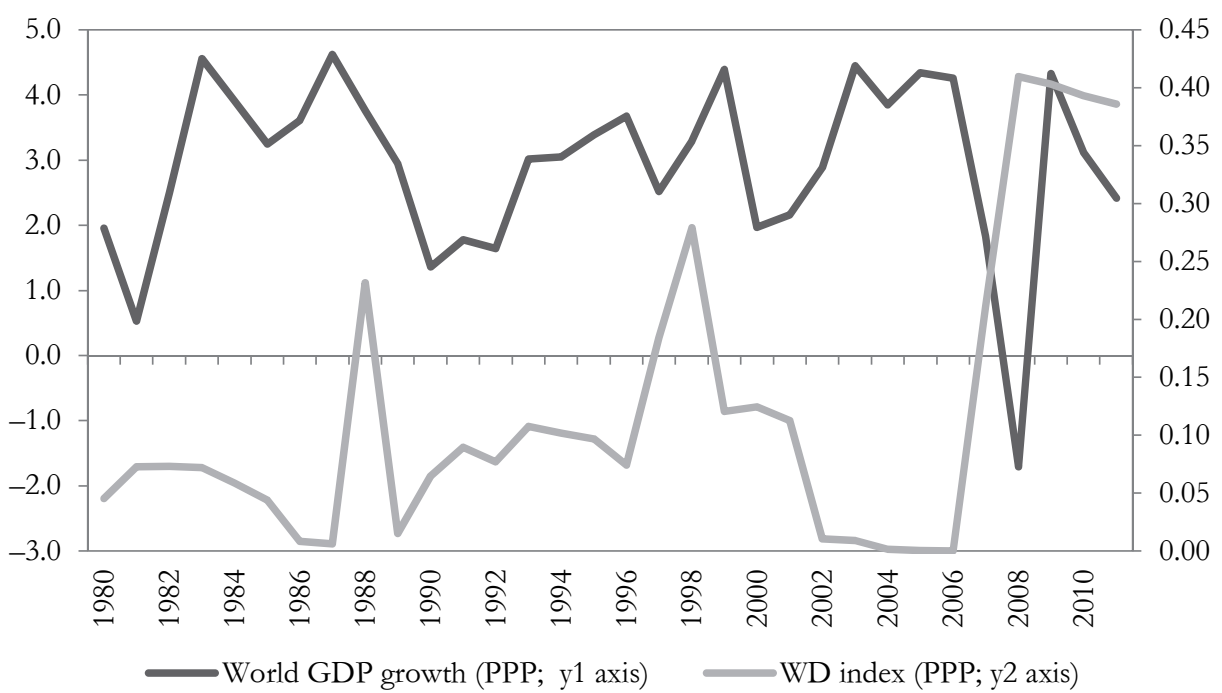

To explain this behaviour in former crises, we use the series of first differences of $W D^{1}$, because it is $I(1)$ (the Dickey-Fuller statistic is -1.5 in levels and -5.9 for the first differences), while for the worldwide GDP growth, we use the original series, since it is $I(0)$ (the Dickey-Fuller statistic is -4.3 , significant at the $1 \%$ level). Figure 4 shows that when the differences in $W D^{1}$ are positive - indicating that a larger portion of the world GDP is affected by the crises - economic growth slows down. The only exception seems to be around 1998.

If we run a simple regression with $W D^{1}$ (in differences, because it is $I(1)$ as the only explanatory variable, we can see that it has a significant and expected negative sign. The results are shown in Table 2. We include a constant (always significant and positive) as well as a trend and lagged growth (neither of which is significant). 
Figure 4

World GDP growth and the differenced WD index

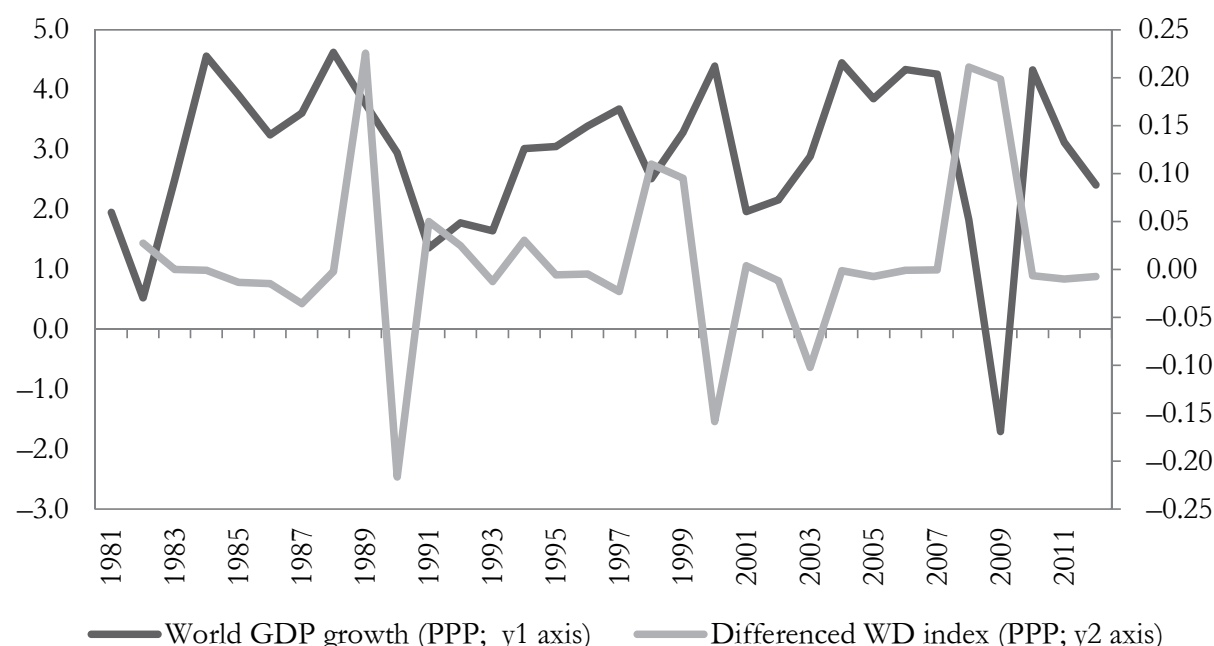

Table 2

Regression results

\begin{tabular}{|c|c|c|c|}
\hline \multirow{2}{*}{ Variable } & (1) & (2) & (3) \\
\hline & \multicolumn{3}{|c|}{ wgrowth } \\
\hline$W D$ & $\begin{array}{c}-5.99 * * \\
(2.59)\end{array}$ & $\begin{array}{c}-5.99 * * \\
(2.65)\end{array}$ & $\begin{array}{c}-6.17 * * \\
(2.55)\end{array}$ \\
\hline Trend & & $\begin{array}{c}0.00 \\
(0.03)\end{array}$ & \\
\hline Lwgrowth & & & $\begin{array}{c}0.24 \\
(0.17)\end{array}$ \\
\hline Constant & $\begin{array}{l}3.02 * * * \\
(0.23)\end{array}$ & $\begin{array}{l}3.02 * * * \\
(0.50)\end{array}$ & $\begin{array}{l}2.33 * * * \\
(0.54)\end{array}$ \\
\hline Observations & 31 & 31 & 31 \\
\hline$R^{2}$ & 0.16 & 0.16 & 0.21 \\
\hline
\end{tabular}

Note: Standard errors in parentheses. ${ }^{* * *} p<0.01,{ }^{* *} p<0.05$. wgrowth: world GDP growth.

This simple exercise seems to indicate that our indices (the case of $W D^{2}$ is similar) capture the intended behaviour of crises - that of disruptive events that affect, in this case, the world economy.

Regional Statistics, Vol. 9. No. 1. 2019: 3-12; DOI: 10.15196/RS090108 


\section{Conclusion}

This paper proposes a very natural definition of indices that could provide a measure for world economic distress in any given year. We define them as the proportion of the world GDP (either measured in PPP or in current USD) affected by a country-level crisis. By their construction, these indices satisfy the necessary properties that imply that they are faithful and fair representations of how country crises impact world economy by affecting countries' respective GDPs.

In section 4, we related the behaviour of these indices to the growth of the world's GDP. We have shown that they have a degree of explanatory power and can therefore be used in further and more complex analyses. More work is required to ensure that these indices will be efficient explanatory variables in general macroeconomic contexts.

\section{REFERENCES}

AKBASH, K. S.-PASICHNYK, N. O.-RIZHNIAK, R. Y. (2018): Generalization of calculation methods for gender indices in demographic and social statistics Regional Statistics 8(2): 170-183. https://doi.org/10.15196/RS080205

ALKIRE, S.-FOSTER, J. (2011): Counting and multidimensional poverty measurement Journal of Public Economics 95(78): 476-487. https://doi.org/10.1016/j.jpubeco.2010.11.006

ANGelopoulou, E.-BAlfoussia, H.-GiBsON, H. D. (2014): Building a financial conditions index for the euro area and selected euro area countries: What does it tell us about the crisis? Economic Modelling 38: 392-403. https://doi.org/10.1016/j.econmod.2014.01.013

BHATTACHARYA, B.-SinHA Roy, T. N. (2009): Forewarning Indicator System for Banking Crisis in India SSRN Working Paper.

Breitenfellner, A.-CuAresma, J. C.-MAYER, P. (2015): Energy inflation and house price corrections Energy Economics 48: 109-116. https://doi.org/10.1016/j.eneco.2014.08.023

CHOI, Y.-DOUADY, R. (2012): Financial crisis dynamics: attempt to define a market instability indicator Quantitative Finance 12(9): 1351-1365. https://doi.org/10.1080/14697688.2011.627880

Laeven, L.-VAlencia, F. (2013): Systemic Banking Crises Database IMF Economic Review 61(2): 225-270.

LouzIs, D. P.-Vouldis, A. T. (2013): A Financial Systemic Stress Index for Greece ECB Working Paper No. 1563.

ReInHart, C. M.-RogofF, K. S. (2009): This Time is Different: Eight Centuries of Financial Folly Princeton University Press, Priceton.

SEN, A. (1976): Poverty: An Ordinal Approach to Measurement Econometrica 44(2): 219-231.

SunANTA, O.-VierTL, R. (2016): Fuzzy models in regional statistics Regional Statistics 6(1): 104-118. https://doi.org/10.15196/RS06106

VALKÓ, G.-FEKETE-FARKAS, M.-KOVÁCS, I. (2017): Indicators for the economic dimension of sustainable agriculture in the European Union Regional Statistics 7(1): 179-196. https://doi.org/10.15196/RS07110

Regional Statistics, Vol. 9. No. 1. 2019: 3-12; DOI: 10.15196/RS090108 